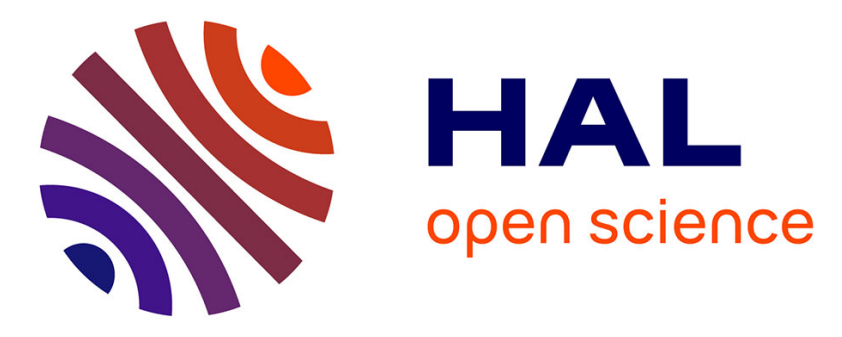

\title{
Management and exploitation of solar resource knowledge
}

Carsten Hoyer-Klick, Christoph Schillings, Marion Schroedter Homscheidt, Hans-Georg Beyer, Dominique Dumortier, Lucien Wald, Lionel Ménard, Benoît Gschwind, Mario Martinoli, Elena Gaboardi, et al.

\section{To cite this version:}

Carsten Hoyer-Klick, Christoph Schillings, Marion Schroedter Homscheidt, Hans-Georg Beyer, Dominique Dumortier, et al.. Management and exploitation of solar resource knowledge. EUROSUN 2008, 1st International Congress on Heating, Cooling and Buildings, Oct 2008, Lisbonne, Portugal. Paper 405. hal-00468443

\section{HAL Id: hal-00468443 \\ https: / hal-mines-paristech.archives-ouvertes.fr/hal-00468443}

Submitted on 30 Mar 2010

HAL is a multi-disciplinary open access archive for the deposit and dissemination of scientific research documents, whether they are published or not. The documents may come from teaching and research institutions in France or abroad, or from public or private research centers.
L'archive ouverte pluridisciplinaire HAL, est destinée au dépôt et à la diffusion de documents scientifiques de niveau recherche, publiés ou non, émanant des établissements d'enseignement et de recherche français ou étrangers, des laboratoires publics ou privés. 


\title{
Management and Exploitation of Solar Resource Knowledge
}

\author{
C. Hoyer-Klick ${ }^{1 *}$, H.G. Beyer ${ }^{2}$, D. Dumortier ${ }^{3}$, M. Schroedter-Homscheidt ${ }^{4}$, L. Wald ${ }^{5}$, M. \\ Martinoli $^{6}$, C. Schilings ${ }^{1}$, B. Gschwind ${ }^{5}$, L. Menard ${ }^{5}$, E. Gaboardi ${ }^{6}$, L. Ramirez-Santigosa ${ }^{7}, J$

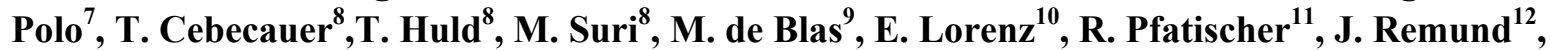 \\ P. Ineichen ${ }^{13}$, A. Tsvetkov ${ }^{14}$, J. Hofierka ${ }^{15}$ \\ ${ }^{1}$ German Aerospace Center (DLR), Institute of Technical Thermodynamics, 70569 Stuttgart, Germany \\ ${ }^{2}$ Hochschule Magdeburg-Standal, Germany. ${ }^{3}$ Ecole Nationale des Travaus Publics de l'Etat (ENTPE), France \\ ${ }^{4}$ German Aerospace Center, German Remote Sensing Data Center, Germany ${ }^{5}$ Ecole des Mines de Paris, France \\ ${ }^{6}$ Icons srl., Italy ${ }^{7}$ CIEMAT, Spain ${ }^{8}$ European Commission, Joint Research Center, Institute for Energy, Italy \\ ${ }^{9}$ Universidad Publica de Navarra, Spain ${ }^{10}$ Oldenburg University, Energy- and Semiconductor Research Lab, \\ Germany ${ }^{11}$ meteocontrol GmbH, Germany ${ }^{12}$ Meteotest, Switzerland ${ }^{13}$ University of Geneva, Switzerland \\ ${ }^{14}$ Voeikov Main Geophysical Observatory, World Radiation Data Center, Russia \\ ${ }^{15}$ University of Presov, Slovakia \\ * Corresponding Author, carsten.hoyer-klick@dlr.de
}

\begin{abstract}
Knowledge of the solar energy resource is essential for the planning and operation of solar energy systems. In past years there has been substantial European and national funding to develop information systems on solar radiation data, leading to the situations that several data bases exist in parallel, developed by different approaches, various spatial and temporal coverages and resolutions including those exploiting satellite data. The user of these products may end up with different results for the same requested sites. To better guide the users, a benchmarking exercise is under preparation. A set of reference data has been collected and benchmarking measures and rules have been defined. The results of the benchmarking and the feedback from stakeholders will be integrated into a guide of best practices in the application of solar resource knowledge. Access to data has been quite fragmented. Each service has its own way of access to the data and delivery format. A new broker portal based on the experience of the project Soda aims to unify and ease the access to distributed data sources and applications providing solar resource information.
\end{abstract}

Keywords: Solar resource information, benchmarking, access to data, user guidance

\section{Introduction}

Knowledge of the solar energy resource is essential for the planning and operation of solar energy systems. In past years there has been substantial funding from the European Commission to develop information systems on solar radiation data, such as the European Solar Radiation Atlas (ESRA), the projects SoDa, Satel-Light, PVGIS, PVSAT, PVSAT-2 or Heliosat-3 and the Envisolar project of the European Space Agency (ESA). In addition national services were set up as Meteonorm by Meteotest in Switzerland and SOLEMI by DLR in Germany. The information on available databases and integrated systems has been summarised and later updated in [1,2]. From the regional point of view, the projects focused mainly on Europe or its regions, leading to the situation that several different data bases exist in parallel developed by different approaches, various spatial and temporal coverages and 
different resolutions including those exploiting satellite data. The users comparing information from different data sources for the requested sites may end up with uncertainty that is difficult to deal with.

Large steps forward have been made for the benefit of research, renewable energy industry, policy making and the environment. Nevertheless, these multiple efforts have led to a fragmentation and uncoordinated access: different sources of information and solar radiation products are now available, but uncertainty about their quality remains. At the same time, communities of users lack common understanding how to exploit the developed knowledge.

The project MESoR started in June 2007 and aims at removing the uncertainty and improving the management of the solar energy resource knowledge. The results of past and present large-scale initiatives in Europe, will be integrated, standardised and disseminated in a harmonised way to facilitate their effective exploitation by stakeholders. The project will contribute to preparation of the future roadmap for R\&D and strengthening the European position in the international field.

The project includes activities in user guidance (benchmarking of models and data sets; handbook of best practices), unification of access to information (use of advanced information technologies; offering one-stop-access to several databases), connecting to other initiatives (INSPIRE of the EU, POWER of the NASA, SHC and PVPS of the IEA, GMES/GEO) and to related scientific communities (energy, meteorology, geography, medicine, ecology), and information dissemination (stakeholders involvement, future $\mathrm{R} \& \mathrm{D}$, communication).

\section{User guidance}

\subsection{User survey}

One of main objectives of the MESoR project is the involvement of key stakeholders throughout the project. Their first task was the participation in a user survey which was conducted as an interview via telephone calls or e-mail. The survey performed a comparative analysis of various solar radiation platforms concerning technical aspects but also addressing usability, integration and pre-commercial information. This analysis based on the evaluations expressed by actual "top-users" and "topcustomers" of the platforms. The sample has been composed by current users of the services belonging to various academic, scientific, industrial and business categories, from public and private sectors. The organisations are active in the fields of architecture/building, PV and other solar applications. The initial sample of 53 was selected by each partner according to the criteria of importance, frequency of usage and attitude to scientific cooperation.

The collected answers indicate a very high degree of awareness about the analysed issues. This is witnessed by the fact that most of the respondents use multiple services, they have a deep knowledge of each service, are able to compare the various services and to highlight the related points of strength and weakness.

The survey detected a gap between expectations and the satisfaction as for quality and accuracy of some parameters, reliability of data measurement and calculation, comparability of data across the services and personalisation of services.

The users expect a truly new and integrated service that offers standardised data and protocols.

\subsection{Benchmarking}

Benchmarking is the largest activity within the MESoR project. The aim of the benchmarking exercise is to establish a coherent set of benchmarking rules and reference data sets to enable a transparent and comparable evaluation of the different solar radiation data sources. The rules are developed in 
conjunction with the IEA Task 36 on "Solar Resource Management" of the Solar Heating and Cooling Implementing Agreement and shall serve as a standard for benchmarking to make results comparable.

\subsubsection{Reference data}

This activity focuses on collection of high quality ground measurements which can be used as a reference in the benchmarking exercises. The measurements should be conducted with high accuracy, high frequency and traceable maintenance of the equipment. Data has been collected from the Baseline surface radiation network (BSRN), International Daylight Measurement programme (IDMP), the meteomedia network, the World Radiation Data Center (WRDC) and the Global Atmospheric Watch (GAW) programme. In addition further measurements were collected from scientific institutions, providing they fulfil the quality criteria above.

Table 1: Physical limits for quality control, with: $\mathrm{G}_{0}$ : irradiance available at the top of atmosphere; $\mathrm{GV}_{0}$ : illuminance available at the top of atmosphere; $\theta_{\mathrm{z}}$ : solar zenith angle

\begin{tabular}{lll}
\hline Parameter & Min & Max \\
\hline Global irradiance & $-4 \frac{W}{m^{2}}$ & $G_{0} \times 1.5\left(\cos \theta_{z}\right)^{1.2}+100 \frac{W}{m^{2}}$ \\
\hline Diffuse irradiance & $-4 \frac{W}{m^{2}}$ & $G_{0} \times 0.95\left(\cos \theta_{z}\right)^{1.2}+50 \frac{W}{m^{2}}$ \\
\hline Direct irradiance & $-4 \frac{W}{m^{2}}$ & $G_{0}$ \\
\hline Global illuminance & $0 \operatorname{lux}$ & $G V_{0} \times 1.5\left(\cos \theta_{z}\right)^{1.2}+10000$ lux \\
\hline Diffuse illuminance & $0 \operatorname{lux}$ & $G V_{0} \times 0.95\left(\cos \theta_{z}\right)^{1.2}+5000 l u x$ \\
\hline Direct illuminance & $0 \operatorname{lux}$ & $G V_{0}$ \\
\hline
\end{tabular}

Table 2. Parameters for checking the coherence of component parameters [5].

\begin{tabular}{llc}
\hline \multicolumn{1}{c}{ Parameter } & condition & Limits \\
\hline$\frac{G_{\text {Global }}}{G_{\text {Diffuse }}+G_{\text {Direct }} \cos \theta_{z}}$ & $\theta_{z}<75^{\circ}, G_{\text {Diffuse }}+G_{\text {Direct }} \cos \theta_{z}>50 \frac{\mathrm{W}}{\mathrm{m}^{2}}$ & $1.0 \pm 8 \%$ \\
\hline$\frac{G_{\text {Global }}}{G_{\text {Diffuse }}+G_{\text {Direct }} \cos \theta_{z}}$ & $93^{\circ}>\theta_{z}>75^{\circ}, G_{\text {Diffuse }}+G_{\text {Direct }} \cos \theta_{z}>50 \frac{\mathrm{W}}{\mathrm{m}^{2}}$ & $1.0 \pm 15 \%$ \\
\hline$\frac{G_{\text {Diffuse }}}{G_{\text {Global }}}$ & $\theta_{z}<75^{\circ}, G_{\text {Global }}>50 \frac{\mathrm{W}}{\mathrm{m}^{2}}$ & $<1.05$ \\
\hline$\frac{G_{\text {Diffuse }}}{G_{\text {Global }}}$ & $93^{\circ}>\theta_{z}>75^{\circ}, G_{\text {Global }}>50 \frac{\mathrm{W}}{\mathrm{m}^{2}}$ & $<1.10$ \\
\hline
\end{tabular}

A common quality control procedure has been defined for all broadband time series data. The parameters for the quality assessment have been deducted from the Baseline Surface Radiation Network Operation Manual [3] and operational experience of the partners involved. All data is flagged if:

- It is within the physical possible limits. The applied physical limits are shown in table 1 .

- It is lower than it would be in a dry and clean atmosphere. We apply the e.g. the Bird clear sky model (Model C in [4]) with aerosols and water vapour set to zero. 
- The components of direct, diffuse and global parameters are coherent (if all are available). The conditions and limits are described in table 2.

Only values passing all tests will be used in the benchmarking exercises.

\subsubsection{Benchmarking measures and rules}

Benchmarking of solar radiation products can be done in different ways. If a kind of reference data is available which is assumed to be the "truth", the modelled data sets can be compared and ranked how well they represent the reference data. But there is not always reference data available: e.g. for solar radiation spatial products (maps). Here benchmarking can assess the uncertainty of mapping products by their cross-comparison.

For site specific time series there are a number of different measures for benchmarking. A first set is based on first order statistics. These are the well known bias, root mean square deviations, standard deviations, their relative values to the average of the data set and the correlation coefficient. They compare how well data pairs at the same point of time compare with each other. They are important if one needs an exact representation of real data, e.g. for evaluations of real operating systems or forecasts of solar radiation parameters.

This exact match is not always important, e.g. for system design studies. Here the similarity of statistical properties as frequency distributions is more important than the exact match of data pairs. The MESoR project therefore suggests a number of parameters based on second order statistics [6].

Besides a common set of measures the selection of valid pairs of data is of importance to achieve comparable results. Valid data pairs should have passed the quality control procedure as described above, measured global horizontal ground data should be above zero (valid measurement, sun above the horizon) and the modelled data should be valid. Average values (e.g. for relative bias or standard deviations) are calculated based on the valid data pairs. If averages from multiple stations are to be calculated, all data pairs should be treated with the same weight. Averages should be calculated from the complete data set and not from the single stations results. This gets relevant if the stations have different numbers valid data pairs.

A benchmarking exercise applying the measures and rules to available data bases within Europe will be done in the second half of 2008.

Benchmarking of angular distributions is yet difficult, as there are a number of different instruments available with very different characteristics in terms of number of sensors, acquired parameters (irradiance, radiance, luminance), geometry of the measurement directions in the sky hemisphere, spectral sensitivity of the sensors, aperture angle, size and shape and the sensors and the sensors linearity and dynamics. Further, there are only very few measurements available so far.

Solar maps can be benchmarked in two ways, either point based or map based. The point based benchmarking is similar to the time series benchmarking. Data is extracted from the maps and compared to the measurements ("ground truth"). First and second order statistics can be applied. Map based cross comparison of solar radiation provides means for improved understanding of regional distribution of the uncertainty by combining all existing resources (calculating the average of all) and quantifying their mutual agreement by the means of standard deviation. A sample evaluation has been done with five spatial data bases: ESRA, PVGIS, Meteonorm, Satel-light and NASE SSE. 

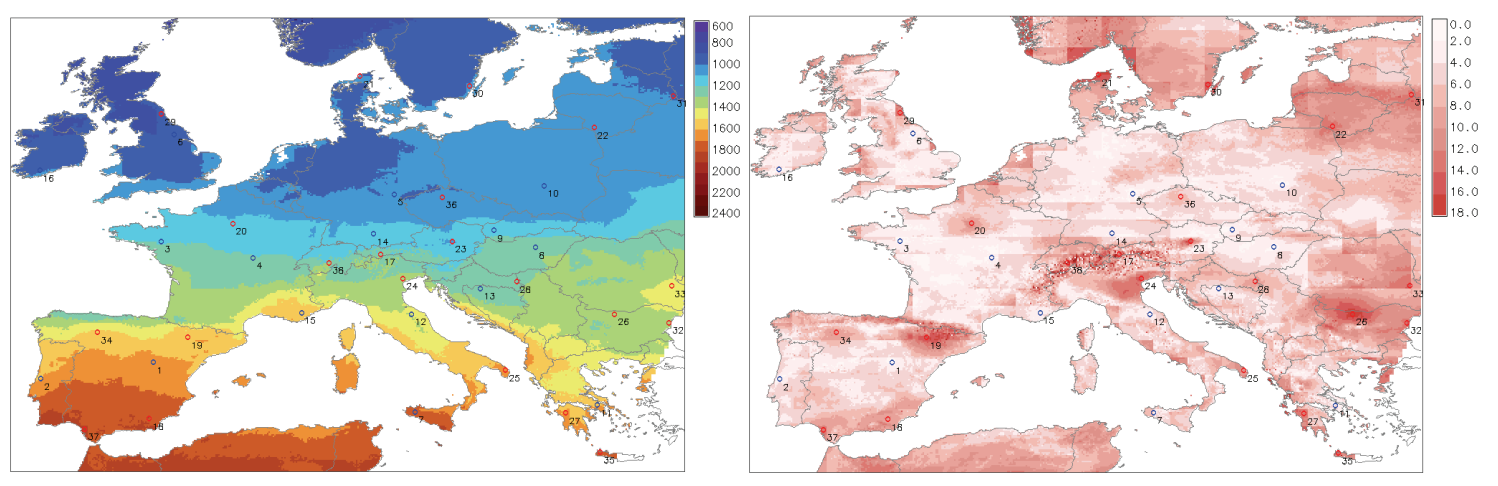

Fig. 1: Yearly sum of global horizontal irradiation, average of all five data bases $\left[\mathrm{kWh} / \mathrm{m}^{2}\right]$ (left), uncertainty at $95 \%$ confidence interval from the comparison of the five data bases. [\%] (right).

A set of benchmarks has been proposed to evaluate solar radiation forecasts. Depending on the application different methods to assess prediction quality are appropriate. For the users of the forecast the verification scheme should be kept as simple as possible and be reduced to a minimum set of accuracy measures. Statistical measures are similar to time series but need to be adapted to forecast specific issues. Forecast should not only be evaluated against the measured data but also against reference models as persistence or autoregressive models to show the advantage of a forecasting system. For forecasting not only the quality of the prediction of a single site is of interest but also the accuracy of prediction of an ensemble of distributed sites e.g. feeding into an electricity grid node.

\subsection{User guide of best practices}

User guidance is one of the main objectives of the MESoR project. This will be realized by the development of a guide of best practices in the application of solar resource data. The above described benchmarking will be one chapter in this guide. The results will give the users a better indication of the uncertainty of the available data sources and which data bases are suitable for different applications. Best practices in the application of solar resource information will be demonstrated in use cases. The applications taken into account by the guide will cover photovoltaics, solar thermal, solar concentrating and daylighting systems. As a basis it will cover requirements and examples for the design of these systems. Further it will cover solar forecasting applications.

\subsection{Roadmap}

Based on the feedback from the stakeholders and the benchmarking results road map documents are foreseen within the MESoR project. They will cover future research objectives in the field of solar resources, new solar radiation services to faster deploy the market for solar energy applications and optimize grid integration and recommendations for an improved Earth Observation system to better support solar energy.

\section{Unifying Access}

The second major objective of the MESoR project is to unify and ease access to solar resource information. This builds upon experiences made within the SoDa portal, adopting mapping features from PVGIS web system. SoDa was build with proprietary software and communication protocols. As the World Wide Web evolved over recent years, the new MESoR portal builds upon open source software with a larger development community and standard web services. This will make the new portal more sustainable in terms of software development and the connection to the portal more easy and open as only widely accepted standards have to be followed. 
The portal will serve as a broker to solar resource information and services. It does not contain and maintain data for itself. It just links data bases and services with a single point of entry and a common user interface. Databases and services have to be hosted by the providers. They keep control over their data and applications.

Metadata are essential to exchange knowledge between applications. They describe objects to be exchanged (e.g. a time series of irradiance, a geographical location, a date...). After a series of consultations with several bodies involved in standards, such as ISO, GEOSS (Global Earth Observation System of Systems), INSPIRE (Infrastructure for Spatial Information in Europe) and national meteorological offices, a thesaurus has been defined which is specific to solar resource. A thesaurus is a set of terms that describe the solar resource.

A prototype of the broker will be set up during the project. A new user interface has been designed. It utilises the API (application programming interface) of Google Maps. Users can therefore use the full capabilities (geographical search, maps and images) of Google to identify their sites and select the right locations or regions. As this interface is easy to use and applied already in many other applications it the user feels familiar with it. The front page of a service gives the site selection window and some descriptive information of the service, as a general description, property rights and credits, inputs and outputs descriptions. The results can be written to the browser window or saved in a specific format (e.g. spreadsheet-compatible). The available data bases can be selected by the menu on top of the page. Fig. 2 shows two sample screenshots of the current prototype (see http://project.mesor.net).

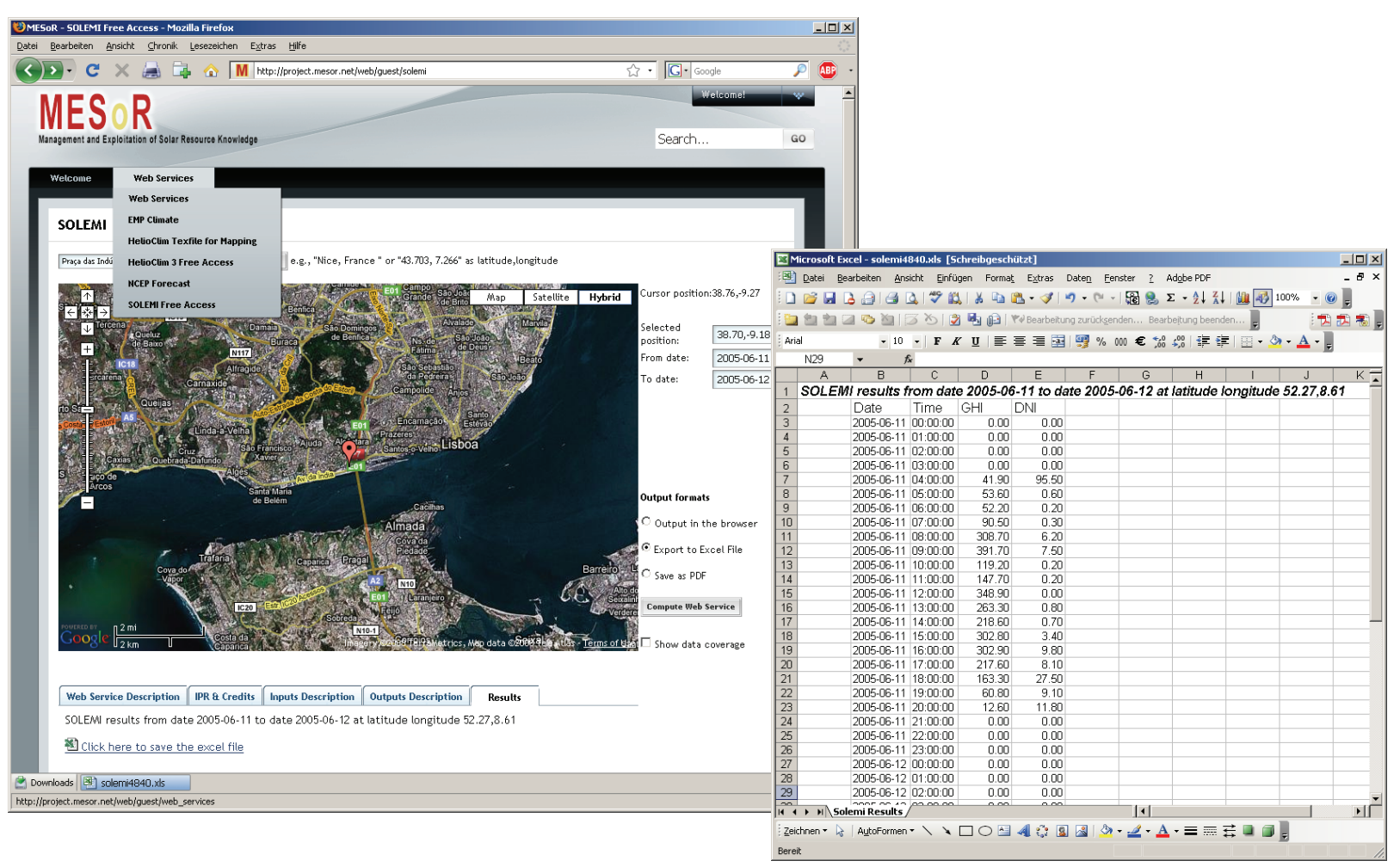

Fig 2. The prototype of the MESoR broker portal. A sample time series has been extracted in an Excel spreadsheet format.

\section{Conclusions}

The project MESoR together with the IEA Task 36 "Solar Resource Knowledge Management" aim at developing better guidance about the energy application of solar resource information. The benchmarking exercise will ease the comparison of different data sources and the standardised rules 
will make accuracy evaluations more transparent and comparable. The guide will help users in the choice of data sources and how to use the data for their specific needs.

The new broker portal aims to ease the access to solar resource data and online applications by serving as single point of entry to a variety of data sources all with a similar look and feel and common data formats. More information about the project can be found at http://www.mesor.net.

\section{References}

[1] L. Wald, (2006). Available databases, products and services. In Dunlop E. D., Wald L., Suri M. (Eds.), Solar Energy Resource Management for Electricity Generation from Local to Global Scale. Nova Science Publishers, New York, pp. 29-41.

[2]M. Súri (2007). Solar resource data and tools for an assessment of photovoltaic systems. In Jäger-Waldau A. (editor), Status Report 2006, Office for Official Publications of the European Communities, Luxembourg, pp. 96-102.

[3] B. McArthur, (2004). Baseline Surface Radiation Network. Operations Manual Version 2.1.

[4] Iqbal, M., 1983. An Introduction to Solar Radiation. Academic Press, New York

[5] C.N. Long, E.G. Dutton (without year). BSRN Global Network recommended QC tests, V2.0 (available at BSRN website http://bsrn.eth.ch).

[6] B. Espinar, L. Ramirez, A. Drews, H.G. Beyer, L.F. Zarzalejo, J. Polo, L. Martin. Analysis of different comparison parameters applied to solar radiation data from satellite and German radiometric stations, Solar Energy (2008) In Press. 